\title{
South Carolina stormwater detention ponds: Sediment accumulation and nutrient sequestration
}

\section{Selyutit}

\section{William Schroer ${ }^{*}$, Claudia Benitez-Nelson ${ }^{1}$, Erik Smith ${ }^{1,2}$, Lori Ziolkowski ${ }^{1}$}

${ }^{1}$ School of the Earth, Ocean, \& Environment ${ }^{2}$ Baruch Institute of Marine and Coastal Sciences *wschroer@geol.sc.edu

University of South Carolina
School of the Earth, Ocean

\section{Introduction}

Stormwater detention ponds are prevalent across South Carolina and receive runoff waters carrying both nutrients and sediments. As sediments accumulate in these ponds, water volume is reduced leading to a decrease in runoff retention. Periodic dredging is required to maintain pond function, but dredging is costly and there is little data available to support how often pond dredging is required. It is further unknown how high nutrient loading effects sediment nutrient sequestration and autochthonous production of organic sediment components. The objectives of this study are to:

- Find the rate of sediment accumulation in these ponds.

- Determine the role coastal stormwater ponds play in the regional cycling of carbon and nutrients.

- Identify the sources of organic matter (external vs. internal) to pond sediments. It is hypothesized that the answers to these questions will be dependent on a host of characteristics including, watershed development density, trophic status, and treatment regime.

\section{Study Area}

Samples were collected from 14 residential stormwater retention ponds located in the coastal regions Georgetown and Horry counties (Figure 1). To the best of our knowledge sample ponds have not been dredged since construction. Ponds were selected to represent a range of watershed development levels, from low density forest dominated to high density urban. Percent impervious surface of pond watershed was used a s a proxy for development density and was calculated using satellite imagery.

Fig. 1 Location of sample ponds

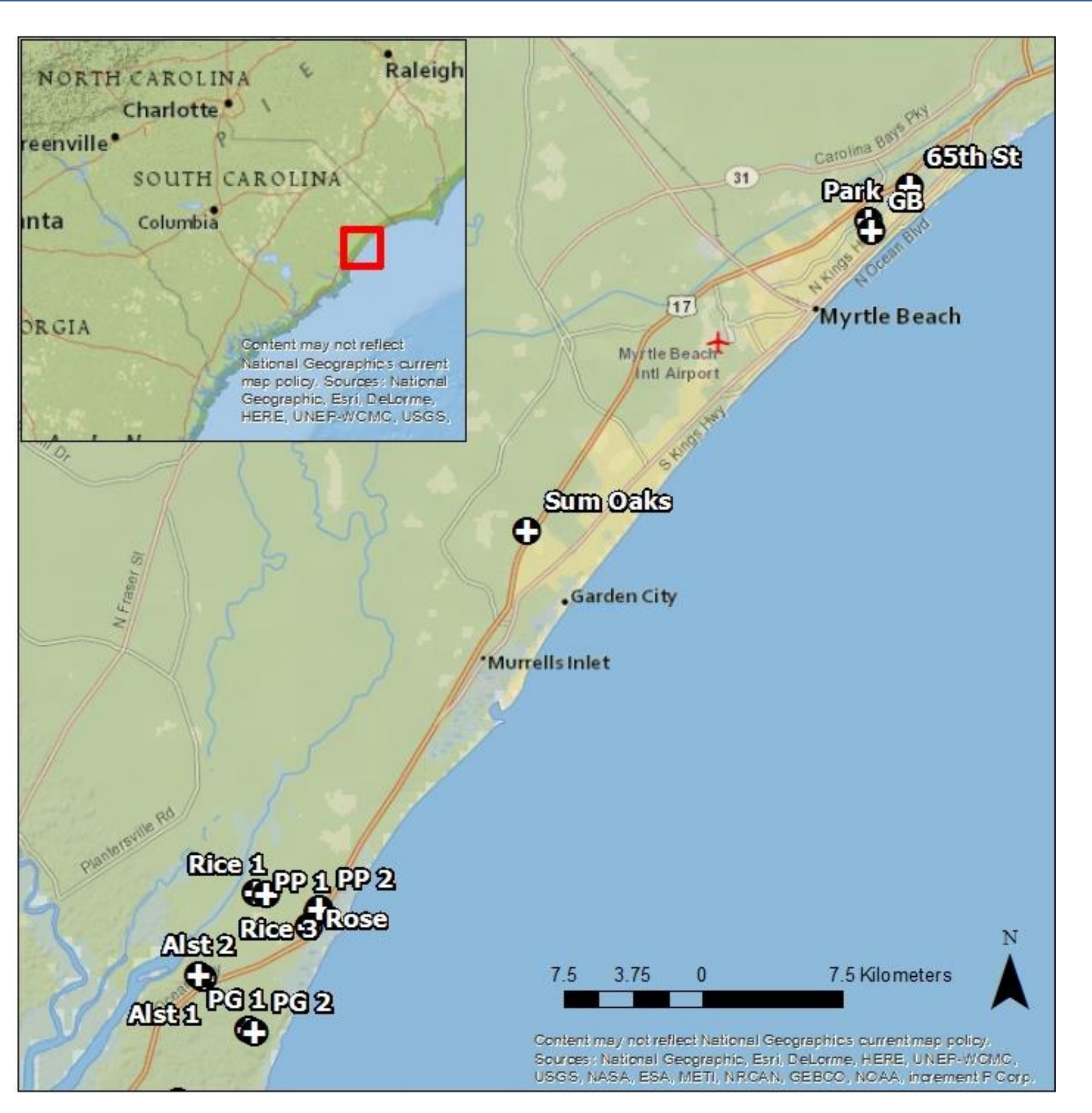

\section{Methods}

From each pond 5-8 cores were collected using a push corer (Figure 2), sectioned at $1 \mathrm{~cm}$ intervals, and freeze dried. Total particulate, inorganic, and organic phosphorus (TPP, PIP, POP, respectively) concentrations were measured colorimetrically after acid hydrolysis (modified from Aspila, et al., 1976). Loss on ignition derived organic carbon was calculated by multiplying the total grams lost after combustion at $500^{\circ} \mathrm{C}$ for $4.5 \mathrm{hr}$ by the constant $0.58 \mathrm{~g} \mathrm{OC} / \mathrm{g} \mathrm{LOI}$ (Waksman, 1936, as cited in Erdtman, 1943). Future carbon and Nitrogen (data not shown) will be measured using a Carlo Erba Elemental Analyzer. Biomarker analysis of $n-$ alkanes in core samples provide insight into the origins of organic matter, e.g., terrestrial or aquatic, within pond sediments. Alkanes are solvent extraction, isolated using silica gel chromatography and quantified using GCMS (modified from Santos, et al., 2010). Lead-210 (half life 22.3 years) activity, for radiometric dating, was determined using a germanium well detector and the age calculated using the Constant Initial Concentration model (Appleby \& Oldfield, 1978) (Krishnaswami, et al., 1971). Additional constraints on age were determined using google earth imagery in combination with real estate records.

\section{Preliminary Results}

Fig. 3 (below) Box plot of sediment accumulation rate $(\mathrm{cm} / \mathrm{yr})$ as determined by the depth of accumulated sediments in surveyed cores divided by the pond age. $X$-axis is in order of watershed \% impervious surface, with purple
indicating $7-15 \%$, Yellow $26-38 \%$, and orange $42-51 \%$.

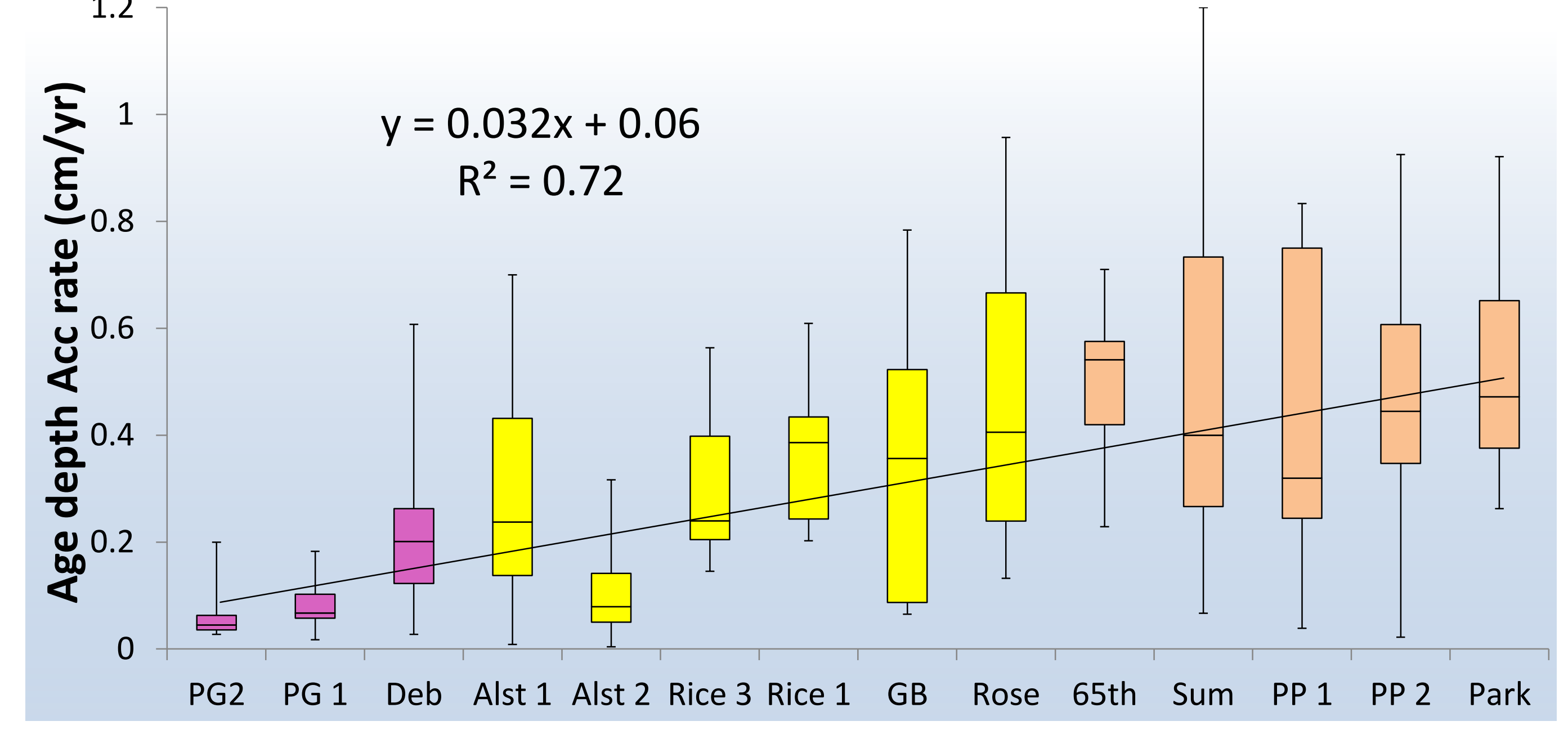

Fig. 4 (below) Example of down core variability of TPP from 3 cores in Park pond. A) TPP vs depth, note the sharp decline in TPP indicates depth of sediment interface. B) Depth is normalized to the sediment interface,
showing that though sedimentation rates vary between core location, similar P loading signatures are apparent.
s.

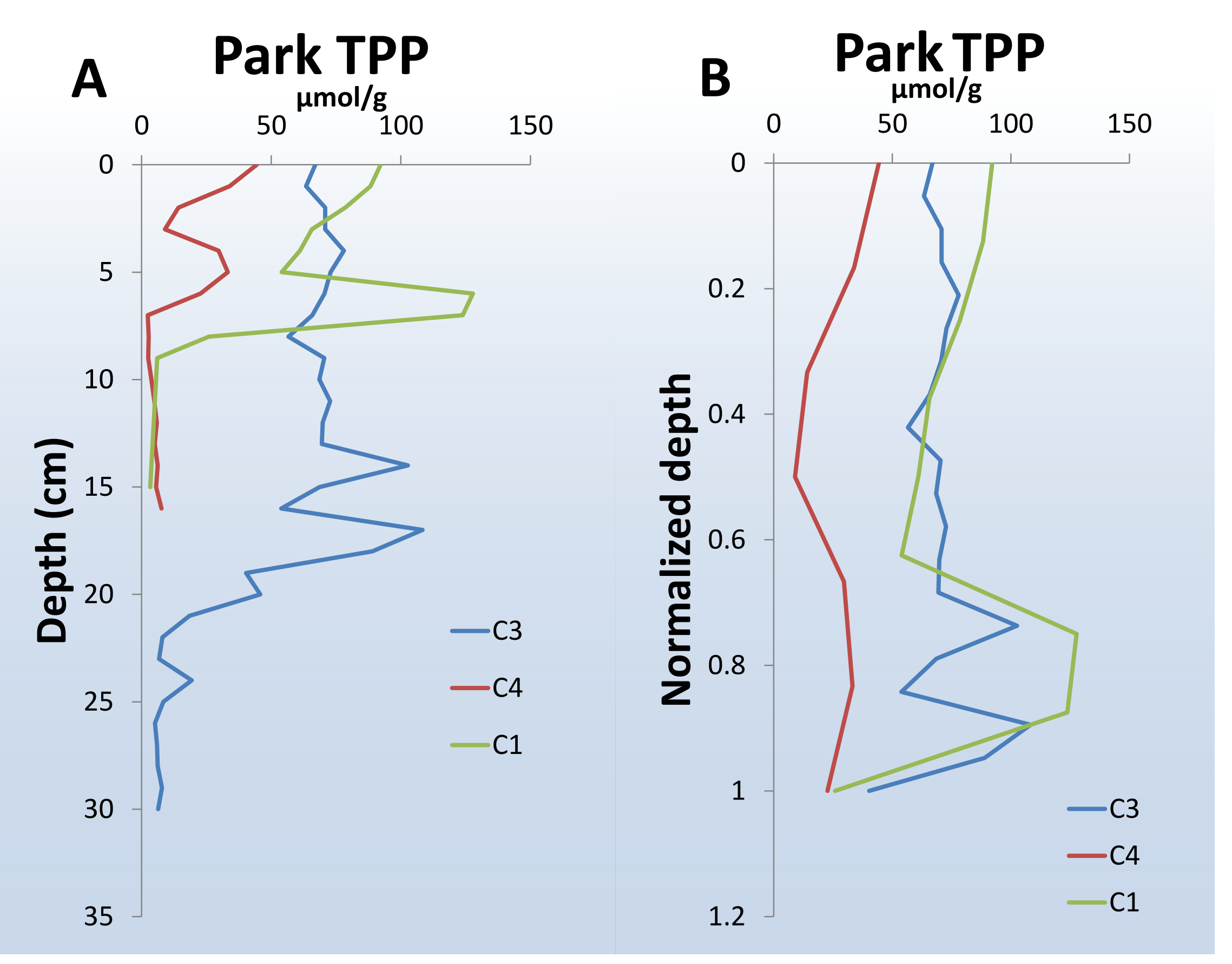

Fig. 5 (below right) Chemical characteristics of sediment reported as concentration per $\mathrm{cm}^{3}$ of wet sediment, not total inventory. Each bar indicates the average for a single core, ponds are in order of increasing \% impervious. Solid horizontal line is mean, dashed lines are 1 std dev. A) Particulate Organic C (POC) as calculated from loss on composition is relatively constant and does not correlate with development density.
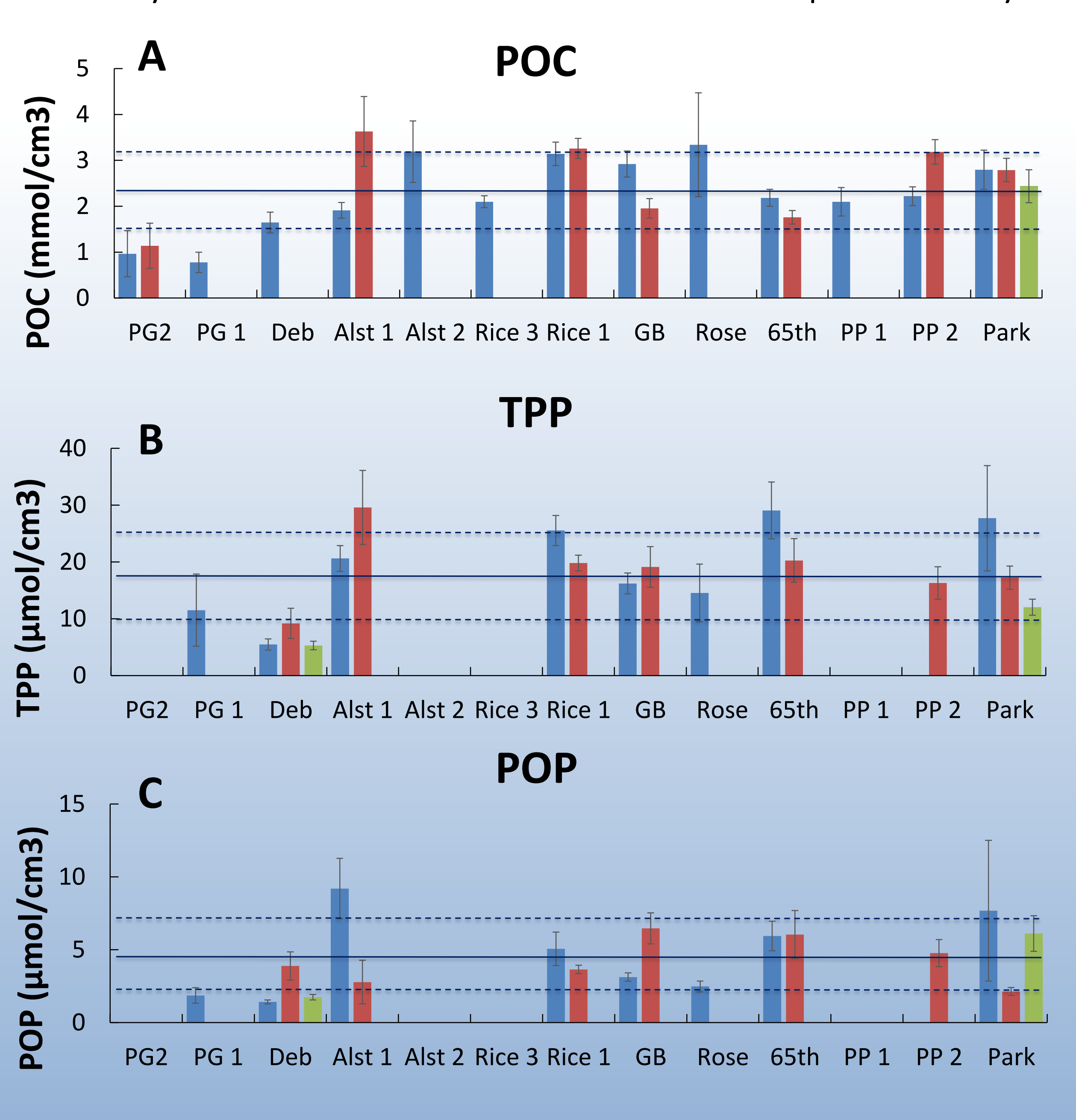
naccumulated sediment $(0-$ $5 \mathrm{~cm})$ of Green Bay C1. The
$\mathrm{C} 17$ peak is associated with algal production while the peak is associated with
terrestrial biomass (Meyers \& Ishiwatari, 1993) The high abundance in $C 31$ relative to $\mathrm{C} 17$ indicates that terrestrial inputs dominate.

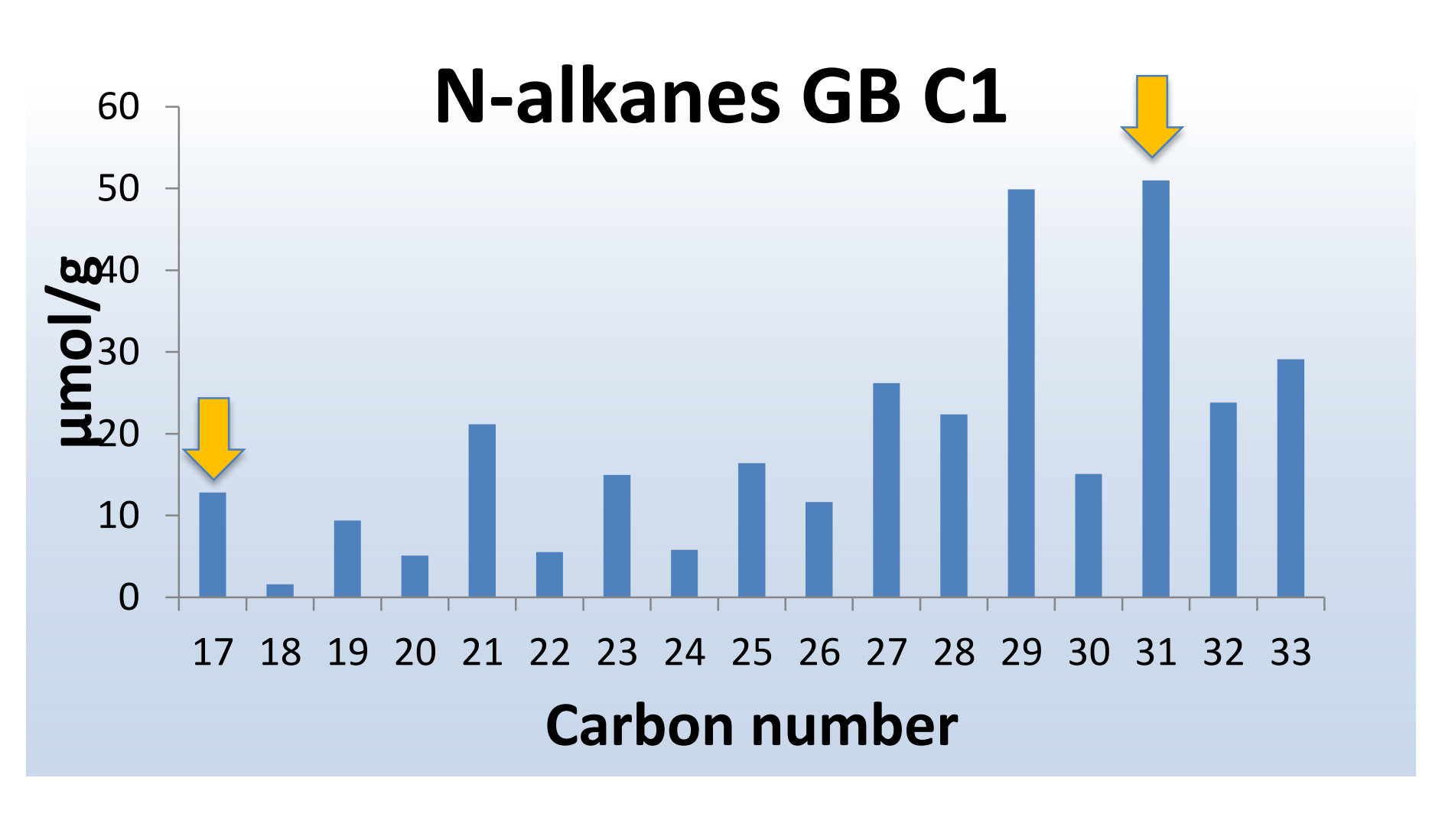

\section{Results, Discussion, and Future Work}

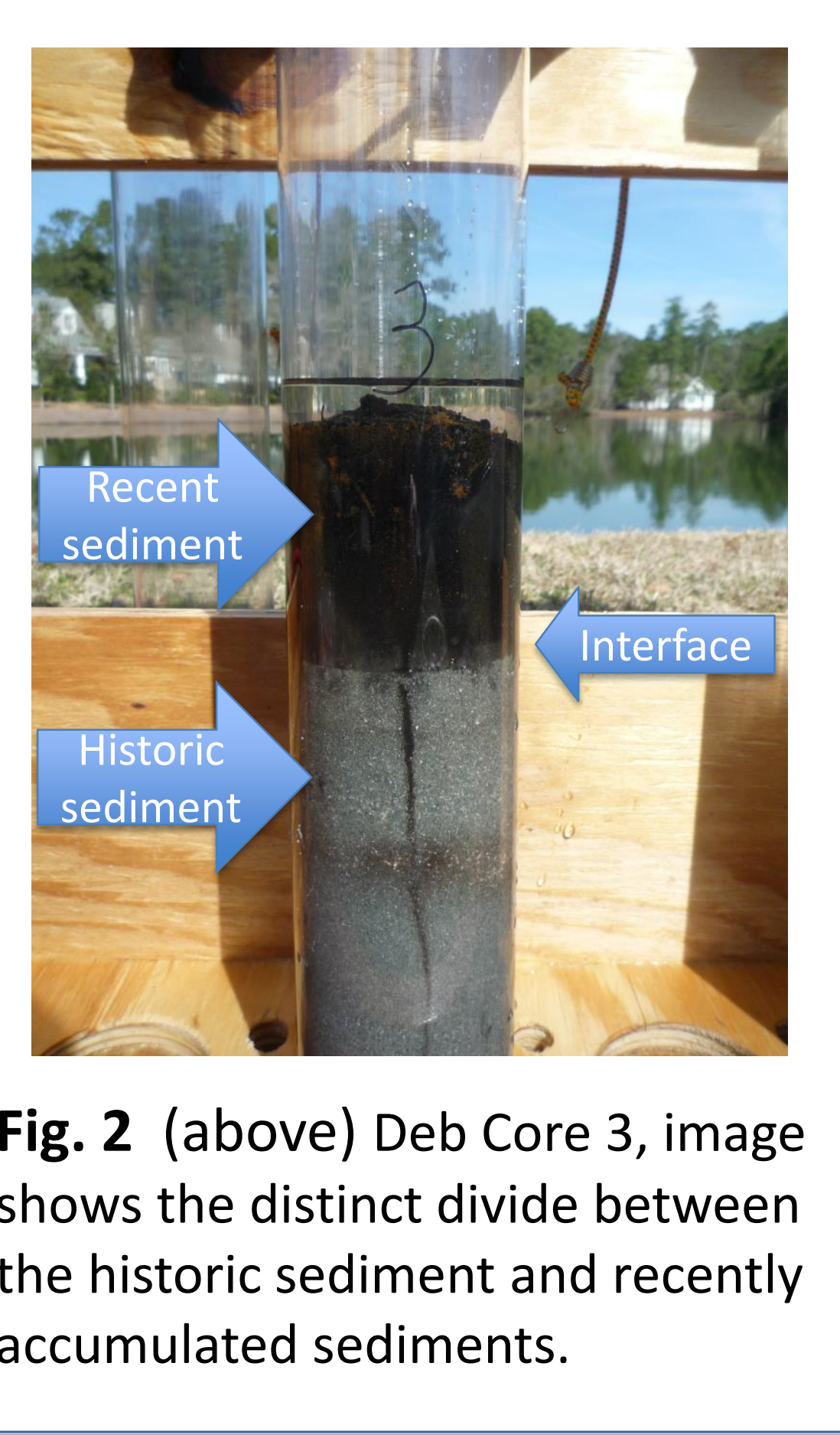

- Accumulated sediments were clearly distinguishable from historic sediments by the obvious differences in grain size, sediment color (Figure 2), and chemical composition. Sediment accumulation is highly variable within ponds but median accumulation rate correlates directly with percent impervious surface of watershed (Pearson's $r=0.846, \mathrm{df}=13, p<0.001$ ) (Figure 3 ). Percent impervious surface may thus be used as a possible predictor of bulk sediment accumulation rate. Median accumulation rates ranged from 0.05 to $0.57 \mathrm{~cm} / \mathrm{yr}$ suggesting that the time required for a $25 \%$ loss in pond volume is significantly longer than previously thought (Fig. 3).

The concentration of nutrients that are buried within sediments, per $\mathrm{cm}^{3}$, is remarkably similar between all ponds considering the vast differences in watershed development and land use (Figures 4 \& 5). This suggests that pond sediment composition is regionally uniform and therefore bulk sediment accumulation rates drive the total pond nutrient burial.

Green Bay is know to have large seasonal algal blooms. However, preliminary alkane biomarker analysis argues that sediment POC is predominantly derived from terrestrial sources (Figure 6). Algal biomass is likely being remineralized prior to sediment burial. As such, the nutrients fixed by algal biomass are not being sequestered, resulting in greater nutrient export to coastal waters.

Moving forward more cores from each pond will be processed in order to fill in gaps in data and better quantify within pond variability. 